\title{
Digital Storytelling as a Creative Teaching Method in Promoting Secondary School Students' Writing Skills
}

\author{
https://doi.org/10.3991/ijim.v13i07.10798 \\ Lim Pei Rong $(\bowtie)$ \\ Sekolah Menengah Kebangsaan Jalan Mengkibol, Kluang Johor, Malaysia \\ prlim0130@gmail.com \\ Norah Md Noor \\ Universiti Teknologi Malaysia, Skudai Johor, Malaysia
}

\begin{abstract}
With the current needs of shaping 21st-century classroom in schools, the use of technology has now become compulsory for teachers to incorporate in the classroom. The exposure to technology is highly necessary for the current generation to prepare them for the future ahead. Digital storytelling is one of the tools available in the market for learning. There is no much research yet found in Malaysia that investigates the usefulness of the digital storytelling in promoting secondary school students' writing skills. Therefore, this research tries to implement one digital storytelling tool in teaching Writing for English Form 1 and tries to identify the elements of digital storytelling tool that might be able to promote students' writing skills. This research involved fifteen Form 1 students. The data was collected through four (4) time series tests in a pre-experimental research study. The students' performance in each treatment were marked according to the Rubrics to Assess Digital Stories and were analysed using Friedman Ranks Test. The finding shows that there is an improvement in students' performance after four treatments of using the Digital Storytelling tools. For the elements of digital storytelling tool that affected after using the digital storytelling tool, the student respondents always applied six elements: 'Overall Purpose of the Story', 'Dramatic Questions', 'Choice of Content', 'Pacing of the Narrative', 'Quality of the Images' and 'Good Grammar and Language Usage'. Furthermore, there is an improvement in student respondents' post-test marks after four treatments of using Storybird. The study shows a relationship between elements of digital storytelling tool in the four treatments and students' writing performance in post-test. All of the elements shows a significant relationship with students' writing performance except for 'Dramatic Questions'.
\end{abstract}

Keywords - Digital Storytelling, creative teaching, 21st-century learning, web 2.0 


\section{$1 \quad$ Introduction}

In this information age, there is an abundance of computer tools that can be used in the language classroom with the concept of the integration of technology. The fastpaced technological changes over the last few years have increased the interest of educators towards the convergence of technology in education. More and more educators have a tendency to shift their teaching style from the familiar medium of the textbook to the medium of the computer screen. Moreover, the birth of Web 2.0 tools has multiplied the possibility of educators in integrating computer technologies in the language learning classroom [1].

[2] emphasised that the integration of Web 2.0 tools will bring a positive effect in the teaching and learning process especially for language learning since they are able to provide multiple opportunities for students' engagement, communication, active learning, self-directed learning and collaborative learning. Thus, teachers are encouraged to use the Web 2.0 tools in their teaching process. Through these Web 2.0 tools, student learning spaces can be extended beyond the walls of the classroom as the web tools bridge the learning spaces across the school, home and even wider community [3]. On top of that, Web 2.0 tools not only support a virtual learning environment but also offer students the opportunities in practicing their language skills in a fascinating way [4].

Digital storytelling is one of the web 2.0 tools that can be used in the language classroom to promote teaching and learning process. Numerous researches in foreign countries have proven that digital storytelling can bring benefits to students. In basic schools in Oya state, [5] discovered that digital storytelling was able to improve kindergarten pupils' achievement in moral instruction. Whereas, in Portugal, [6] proved that the use of digital storytelling among secondary school students encouraged multimodal literacy in education. Additionally, in southern Taiwan, [7]'s research showed that project-based digital storytelling technique improved elementary school students' learning motivation, problem-solving competence as well as their learning achievement.

Despite all of the benefits, schools have yet to give their full attention to the use of digital storytelling in teaching students [8]. At the same time, teachers are still seen as reluctant to integrate technology into teaching $[9,10,11]$. This is due to the reason of using technology in the classroom might spend a lot of time. Lack of the facilities such as LCD and projector as well as the time-consuming in fixing projector and laptop impede the teachers in school from the use of technology in their lesson. One of the respondents in [9]'s study reflected that her primary school students became extremely excited when she was using digital storytelling in her lesson. The class that out of control made her think twice to integrate technology into her lesson again. Nonetheless, it was undeniable that students had positive response and attitude in spite of the problems.

Even though the digital storytelling tool is born to develop students' writing skill, it still has to compatible with current Malaysian English classroom context as well as cater the students with different language proficiency level. On top of that, the digital stories created by the students are needed to assess using an effective grading rubric 
such as the digital storytelling elements that suggested by Robin and Pierson (2005). The elements of digital storytelling are essential and should take into the consideration because they are the one that work in promoting students' writing performance.

\section{Research Objective}

The objective of this research is

- To identify if there is a significant difference in students' writing skills after using the digital storytelling tool.

- To identify the elements of digital storytelling tool that affected after using the digital storytelling tool.

\section{$3 \quad$ Methodology}

The researcher applied the research design of pre-experimental design which called one group time-series test. The student respondents' writing performance would be measured before and after each four treatments were implemented. 15 Form 1 students were involved in this study. The accounts of chosen digital storytelling tool had been signed up beforehand by the researcher for each student respondent. The student respondents were then involved in a tutorial session that lasted for two hours. They were first requested to explore the basic functions of digital storytelling tool independently. Then, the student respondents were asked to produce three pages story with a minimum 10 words per page individually based on the thematic tag given which is 'people'. This introduced the student respondents to the basic features and functions of the chosen digital storytelling and also the steps to do in the treatments later on. The process of conducting four treatments was presented in Figure 1 for an easier glance.

For each treatment, the student respondents were required to produce a five pages story with a minimum of 15 words per page individually. Everyone was provided with a laptop each. The student respondents were requested to write the stories based on the thematic tags given which are 'celebration' for the first treatment, 'technology' for the second treatment, 'sick' for the third treatment and 'shopping' for the fourth treatment. The thematic tags were fixed by the researcher based on the KSSM themes which are 'People \& Culture', 'Science \& Technology', 'Health \& Environment' and 'Consumerism \& Financial Awareness'. The student respondents were encouraged to use their own imagination and creativity in developing the stories. They were given two hours to complete their stories for each treatment. The researcher only assisted them in solving technical problems faced during the activities. Furthermore, during and after the writing activities with the implementation of chosen digital storytelling, two English teachers used the rubrics to assess digital stories created by students. The comments based on the rubrics were given by the English teachers to the student respondents after they completed the first story so they could correct their mistakes thus 
improve their next stories. This step was repeated from the beginning of first treatment until the end of fourth treatment.

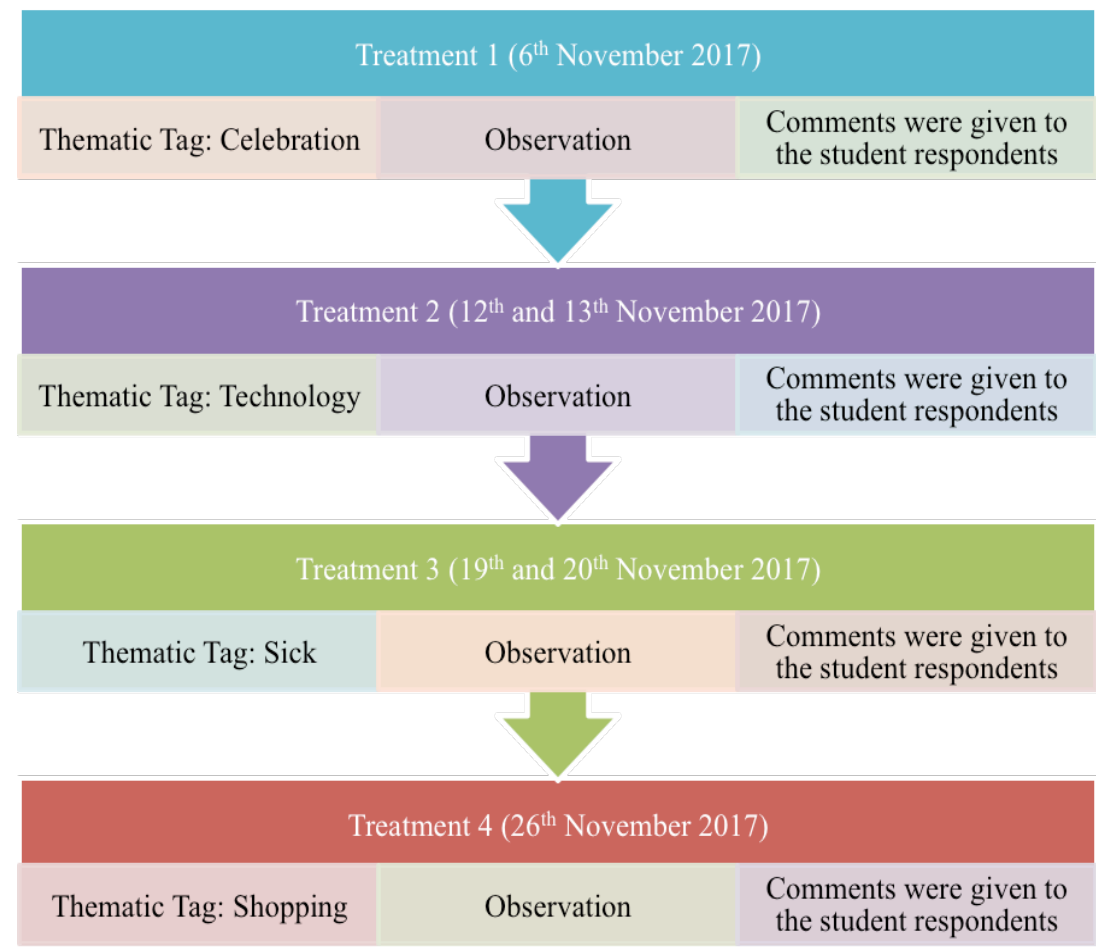

Fig. 1. Process of Conducting Four Treatments

\section{$4 \quad$ Data Analysis and Finding}

This section focuses on the elements of digital storytelling tool that promote students' writing skills. The Center for Digital Storytelling has published seven elements which they believe are the keys in making digital stories to be effective. [12] modified and expanded this traditional version of the seven elements of digital storytelling to the ten elements so it is more applicable to the types of digital stories that created by the students nowadays. Furthermore, another rubrics was prepared based on the previous work done by [13] to help the researcher in assessing the digital stories created by the student respondents thus identifying the elements of digital storytelling tool used.

Additionally, in the effort of improving the observation checklist and rubrics to achieve the research objective, the items had been reduced from ten to eight items. The elements of digital storytelling on 'Clarity of Voice' and 'Use of a Meaningful Audio Soundtrack' were eliminated because there is no audio supported in chosen digital storytelling tool. As a result, only a total of 8 items on the elements of digital storytelling would be given points according to the Rubrics to Assess Digital Stories 
created by Students [12], after each four treatments. To be more details, the four treatments refer to four writing activities that had been conducted with the incorporation of a Digital Storytelling Application named Storybird among 15 student respondents. Besides, each item was corresponding to 1 point, 2 points, 3 points and 4 points. On top of that, the higher the point, the more the student respondents applied that specific element in their digital stories created.

One of elements is the element on dramatic questions. Figure 2 and Figure 3 show an example of 'Dramatic Question' element.

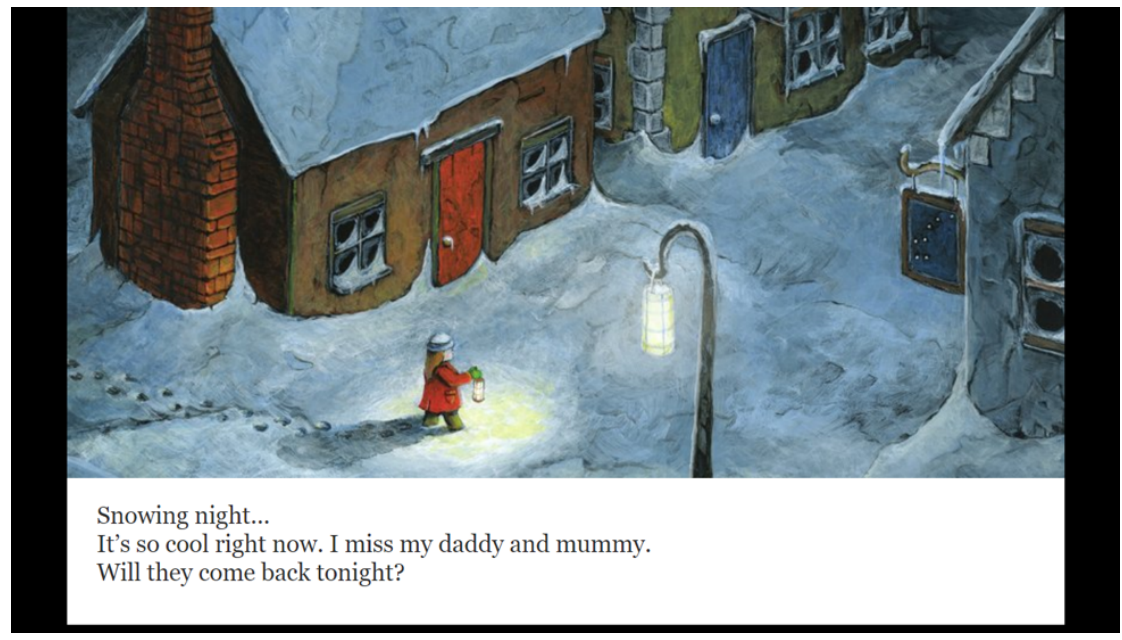

Fig. 2. Example of 'Dramatic Question' Element (Page 1)

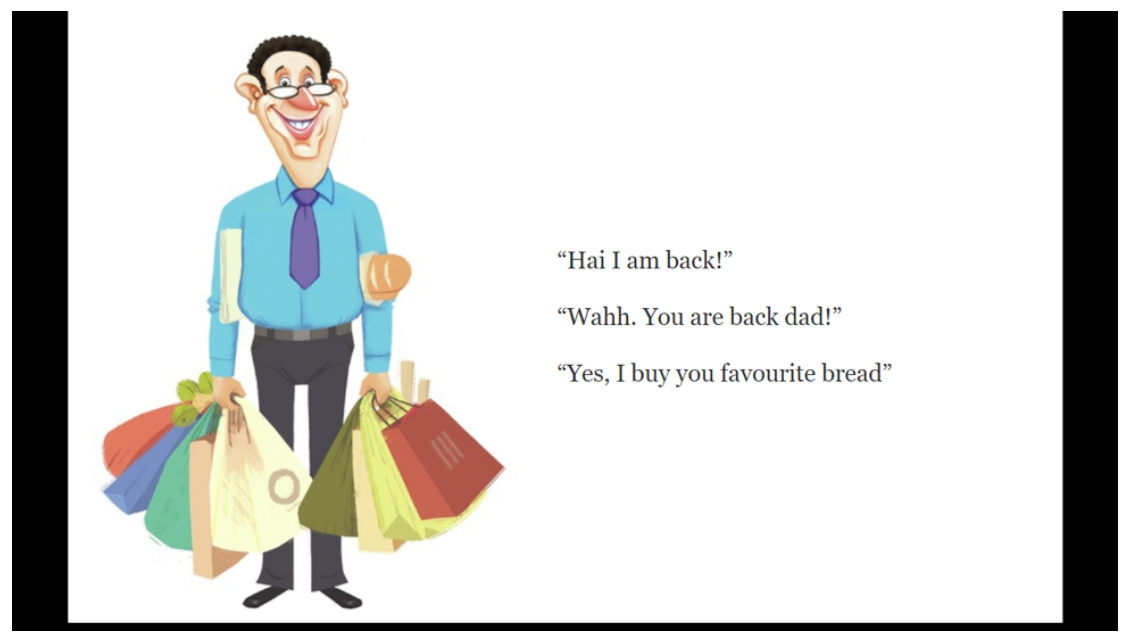

Fig. 3. Example of 'Dramatic Question' Element (Page 2) 
Based on Figure 2 and Figure 3, it can be clearly seen that a meaningful dramatic question 'Will they come back tonight?' is asked and answered within the context of the story. Hence, the student respondent was awarded with full 4 points since he fulfilled the element on dramatic question.

Example of the rubric for the element on quality of the images with Point 1 and Point 4 was shown in Figure 4.
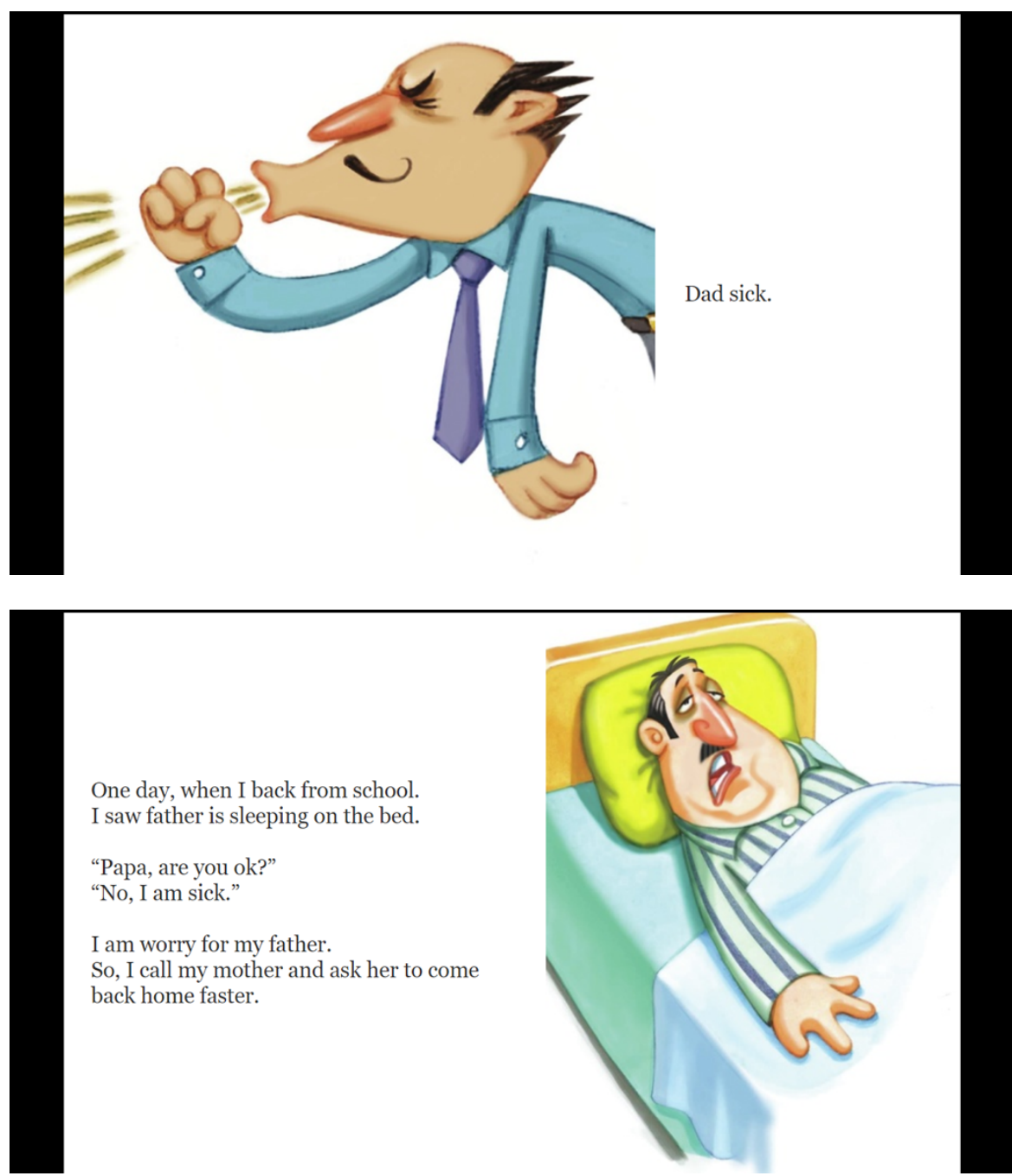

Fig. 4. Example of 'Quality of the Images' Element (1 Points and 4 Points)

Based on Figure 4, it can be clearly seen that there is a noticeable difference between the attempts made by the student respondents. The student respondent who only made a little attempt in using images to create an appropriate atmosphere was award- 
ed with merely 1 point in accomplishing the element on quality of the images. Whereas, another student respondent was awarded with full 4 points in accomplishing the element on quality of the images as he used the images to create a distinct atmosphere that matches with different parts of the story. The images may communicate symbolism and metaphor.

Another example of the rubric for the element on good grammar and language usage with Point 1 and Point 4 were shown in Figure 5 and Figure 6.

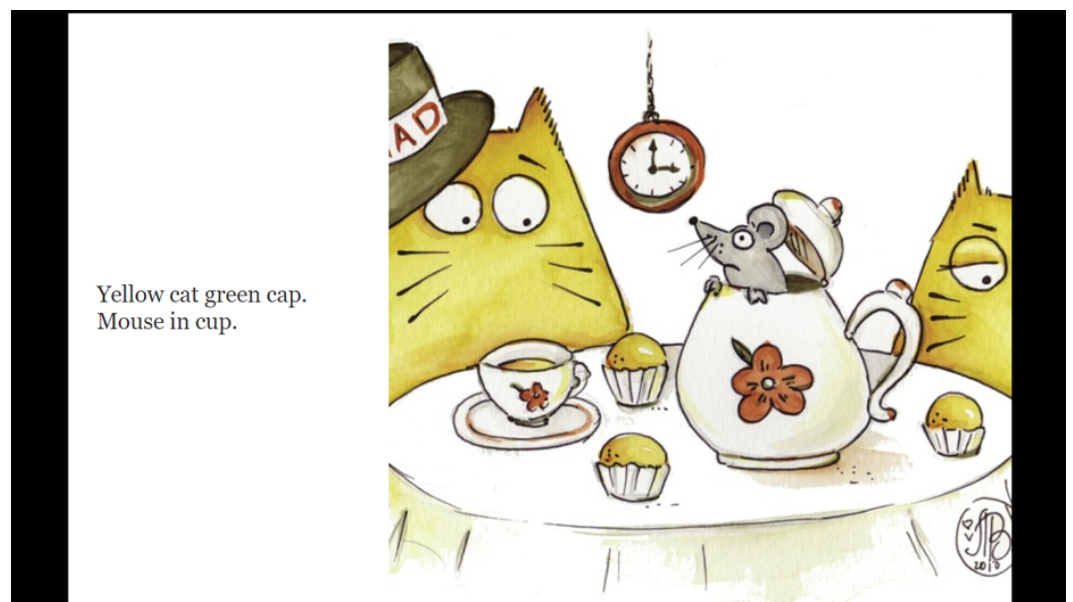

Fig. 5. Example of 'Good Grammar and Language Usage' Element (1 Point)

Based on Figure 5, it can be clearly seen that errors in grammar and usage distracted greatly from the story. Thus, the student respondent was awarded with only 1 point in performing the element on good grammar and language usage.

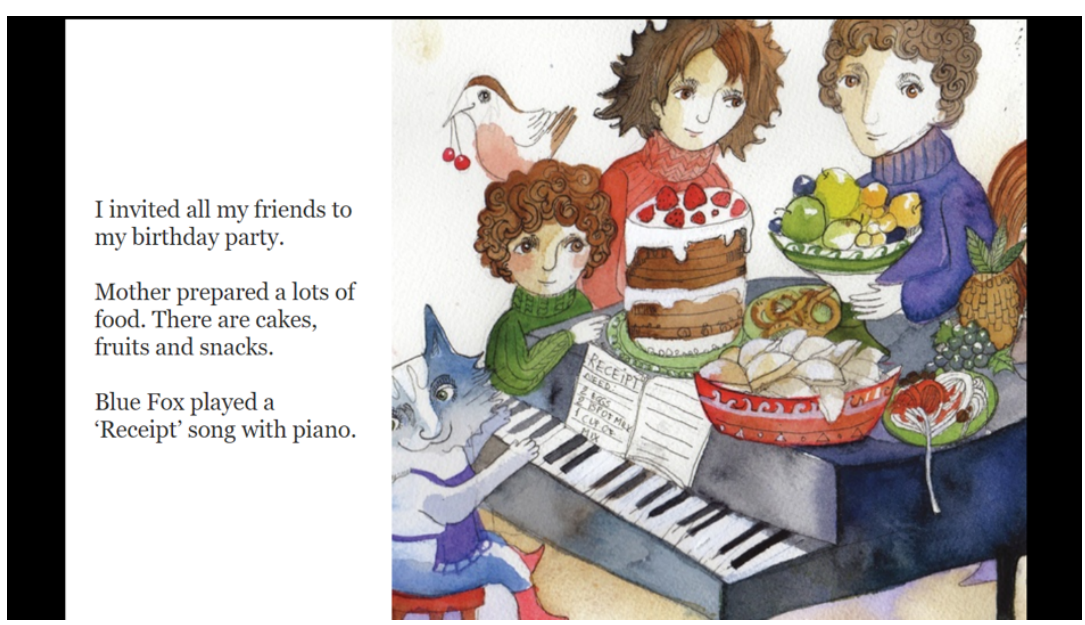

Fig. 6. Example of 'Good Grammar and Language Usage' Element (4 Points) 
Based on Figure 6, it can be clearly seen that grammar and usage were correct and contributed to clarity, style and character development. Thus, the student respondent was awarded with full 4 points in performing the element on good grammar and language usage.

Subsequently, the points of each element of digital storytelling were calculated and keyed in to SPSS program for the purpose of statistical analysis. On the other hand, there were only fifteen student respondents involved in this research. The number of observations $(\mathrm{N})$ is less than 30 and too small to assess normality adequately. For that reason, the non-parametric test of the Friedman Test is used to compare the elements of digital storytelling tool applied by the student respondents throughout the four treatments. The results of the findings as shown below for easier glance.

Table 1. Summary of Elements of Digital Storytelling Tool in Four Treatments

\begin{tabular}{|l|c|c|c|c|c|c|c|c|}
\hline & $\begin{array}{c}\text { Overall } \\
\text { Purpose } \\
\text { of the } \\
\text { Story }\end{array}$ & $\begin{array}{c}\text { Narrators } \\
\text { Point } \\
\text { of View }\end{array}$ & $\begin{array}{c}\text { Dramatic } \\
\text { Question } \\
\text { or } \\
\text { Questions }\end{array}$ & $\begin{array}{c}\text { Choice } \\
\text { of } \\
\text { Content }\end{array}$ & $\begin{array}{c}\text { Pacing } \\
\text { of the } \\
\text { Narrative }\end{array}$ & $\begin{array}{c}\text { Quality } \\
\text { of the } \\
\text { Images }\end{array}$ & $\begin{array}{c}\text { Economy } \\
\text { of the } \\
\text { Story } \\
\text { Detail }\end{array}$ & $\begin{array}{c}\text { Good } \\
\text { Grammar } \\
\text { and } \\
\text { Language } \\
\text { Usage }\end{array}$ \\
\hline Chi-Square & 12.660 & 2.400 & 11.909 & 27.142 & 8.846 & 22.710 & 4.661 & 9.429 \\
\hline Df & 3 & 3 & 3 & 3 & 3 & 3 & 3 & 3 \\
\hline Asymp. Sig. & .005 & .494 & .008 & .000 & .031 & .000 & .198 & .024 \\
\hline
\end{tabular}

Table 1 summarises the Friedman test statistics of the elements of digital storytelling tool in four treatments. The elements of digital storytelling tool that showed a significant difference between four treatments are determined as the elements of digital storytelling that promote student respondents' writing skills. Based on Table 1, it can be clearly seen that the elements of digital storytelling on 'Overall Purpose of the Story', 'Dramatic Question or Questions', 'Choice of Content', 'Pacing of the Narrative', 'Quality of the Images' and 'Good Grammar and Language Usage' have the significant value of $p=0.005, p=0.008, p=0.000, p=0.031, p=0.000$ and $p=0.024$ respectively. The significant value of $\mathrm{p}$ which is less than 0.05 indicates that there was a significant difference on 'Overall Purpose of the Story', 'Dramatic Question or Questions', 'Choice of Content', 'Pacing of the Narrative', 'Quality of the Images' and 'Good Grammar and Language Usage' between the four treatments. Therefore, it can be concluded that all of the elements of digital storytelling tool are the elements of digital storytelling that promote student respondents' writing skills except for 'Narrator's Point of View' and 'Economy of the Story Detail'.

\section{Discussions}

In term of 'Overall Purpose of the Story', the students should create a purpose early on and maintains a clear focus throughout [12]. Thru the four treatments, the student respondents improved themselves from unable to deliver a fairly clear purpose of the story until establish and maintain the clear purpose from beginning to end of the digital story. [14] claimed that a digital story can only be addressed as a good text 
writing if and only if the author establishes a meaningful purpose for the story and maintains the consistency until reaching a reasonable ending.

In term of 'Dramatic Questions', the students should pose a question to arouse the reader's curiosity and gives an answer or explanation by the end of the story. Throughout the four treatments, the student respondents were encouraged to generate questions to draw readers' attention in reading their digital stories. According to [15], students who include the element of asking questions in the creation of digital stories will develop advanced communication skills through the learning on organising ideas, asking questions, expressing opinions as well as constructing narrative stories. It also benefits the students in the way of presenting their thoughts and knowledge in an individual and meaningful way.

From the aspect of 'Choice of Content', the students should make the attempt to use the contents to create a distinct and appropriate atmosphere or tone that matches with different parts of the story [12]. This element is similar with one of the requirements in Pentaksiran Tingkatan 3 (PT3) marking scheme, where the ideas should be welldeveloped and well-organized with main ideas and supporting details for students to score high marks in their English writing section. Hence, student respondents were trained to establish the connection to the topic given as well as to the different parts of the story. This skill had been boosted up in this research with the use of Storybird. [16] stated that digital stories help to actualize abstract concepts, reconstruct conceptual content in a more comprehensible way and also conveying content in a fascinating way.

In term of 'Quality of the Images', the students should make the attempt to use the images to create a distinct and appropriate atmosphere or tone that matches with different parts of the story. The images may communicate symbolism or metaphors [12]. In other words, student respondents used the appropriate content in describing the images thus create a coherence story. Moreover, with the use of the images via a visual platform, Storybird in the four treatments provides a positive impact on the student respondents. According to [17], the verbal codes (words) and non-verbal codes (images) are functionally independent and can have an extra memory response. Therefore, the combination of words and digital pictures are considered to have a positive impact on language learning such as increase the students' interests as well as their willingness in acquiring the English writing skills through the use of Storybird. To be more precise, the stunning artworks in Storybird and the online writing activities are easier in engaging student respondents in the situation of learning the target language skill compared with the normal classroom activities. Thus, the motivation of the learners in the process of learning language can be enhanced with the using of Storybird [18].

From the aspect of 'Good Grammar and Language Usage', the students should use correct grammar and usage in story writing thus contribute to story's clarity, style and character development [12]. This element is similar with two of the requirements in Pentaksiran Tingkatan 3 (PT3) marking scheme, where the language used in writing should be accurate with few first draft slips at the same time vocabulary used should be wide and precise for students to obtain higher grade in their English writing section. Therefore, student respondents were actually trained to produce the writing pieces with minimum grammatical errors as well as use varied and good-choice of vocab- 
ulary in describing the incident or character in the writing. These two skills had been polished again in this research with the use of Storybird. This is then supported by the researches done by $[19,20,21]$. They verified that students' grammar, vocabulary along with writing skills were improved after using Storybird.

Ultimately, through this research, it has been proven that the elements of Storybird play a substantial role in cultivating secondary school students' English writing skills, thus promote their writing performance. [22] claimed that a good digital storytelling tool should cover most of the elements of digital storytelling. [23] also declared that elements of digital storytelling play a role in improving students' writing skills. That is to say, the students were able to create a digital story with exactly the right amount of detail throughout. Furthermore, in case Storybird is not available anymore in the future market, teachers should select the new digital storytelling tools that must have at least the same digital storytelling elements suggested and identified by this research in promoting students' writing performances.

\section{Conclusion}

In conclusion, the student respondents were able to have a hands-on experience of writing a digital story with the artworks provided by Storybird. This was a brand new yet fascinating activity in student respondents' English writing lesson. Also, they recognized their weaknesses in English writing thus tried to amend those flaws and improved their performance through the treatments or known as writing activities with the implementation of Storybird.

As a result, this research has provided a clear picture to the respondents on the integration of digital storytelling, Storybird in promoting writing performance. Similarly, it also proposed a new teaching approach for Malaysian English language teachers in the efforts of improving students' writing skills through the incorporation of technology. Teachers in school are then suggested to enhance their computer selfcompetence through in-service training. The basic usage of digital storytelling, Storybird should be introduced to all the English teachers as the simplicity of technology use will motivate teachers' implementation of ICT in their classroom [24].

\section{Acknowledgement}

The authors are deeply indebted and would like to express our gratitude to the Universiti Teknologi Malaysia for supporting this study under the Research University Vote R.J130000.7716.4J242

\section{References}

[1] G. P. A. Grammatikopoulou, "Benefits, barriers, and prerequisites for Web 2.0 learning activities in the classroom," Interactive Technology, and Smart Education, vol. 13, no. 1, pp. 2-18, 2016. https://doi.org/10.1108/itse-09-2015-0028 
[2] G. Mallia, The Social Classroom: Integrating Social Network Use in Education. Hershey, PA: IGI Global, 2014.

[3] A. Jimoyiannis, "TPACK 2.0: Towards a framework guiding Web 2.0 integration in educational practice,” pp. 83-108, 2015.

[4] J. S. McDougald, "The use of new technologies among in-service Colombian ELT teachers," Colombian Applied Linguistics Journal, vol. 15, no. 2, pp. 247-264, 2013. https://doi.org/10.14483/udistrital.jour.calj.2013.2.a07

[5] L. L. Abiola, "The effect of digital storytelling on kindergarten pupils' achievement in moral instruction in basic schools in Oyo State," IOSR Journal of Research \& Method in Education, vol. 4, no. 5, pp. 26-34, 2014. https://doi.org/10.9790/7388-04552634

[6] C. Gregori-Signes, "Digital storytelling and multimodal literacy in education," vol. 22, pp. 237-250, 2014.

[7] C.-M. Hung, G.-J. Hwang, and I. Huang, "A project-based digital storytelling approach for improving students' learning motivation, problem-solving competence and learning achievement," Educational Technology \& Society, vol. 15, no. 4, pp. 368-379, 2012.

[8] B. Robin, "The effective uses of digital storytelling as a teaching and learning tool," Handbook of Research on Teaching Literacy Through the Communicative and Visual Arts, vol. 2, New York: Lawrence Erlbaum Associates, 2008.

[9] F. Saeed, et al. "Recent trends in information and communication technology," In Proceedings of the 2nd International Conference of Reliable Information and Communication Technology (IRICT 2017). Volume 5 of Lecture Notes on Data Engineering and Communications Technologies. Springer, 2017. https://doi.org/10.1007/978-3-319-59427-9

[10] T.K. Ranjit Singh, and K. Muniandi, "Factors affecting school administrators' choice in adopting ICT tools in schools - The case of Malaysian schools, "International Education Studies, vol. 5, no. 4, pp. 21-30, 2012. https://doi.org/10.5539/ies.v5n4p21

[11] S. M. Thang, L. Y. Sim, N. Mahmud, L. K. Lin, N. A. Zabidi, and K. Ismail, "Enhancing 21st Century Learning Skills Via Digital Storytelling: Voices of Malaysian Teachers and Undergraduates," Procedia - Social and Behavioral Sciences, pp. 489-494, https://doi.org/10.1016/j.sbspro.2014.02.067, 2014.

[12] B. Robin, and M. Pierson, "A multilevel approach to using digital storytelling in the classroom," in Proceedings of Society for Information Technology \& Teacher Education International Conference 2005, C. Crawford et al. (Eds.), pp. 708-716, Chesapeake, VA: AACE, 2005.

[13] Barrett, "The Educational Uses of Digital Storytelling," 2010. [Online]. Available: http://digitalstorytelling.coe.uh.edu/archive/rubrics.html. [Accessed June 22, 2018].

[14] B. S. Şeker, "An evaluation of digital stories created for social studies teaching," 2016.

[15] M. Fasi, "Digital Storytelling in Education, " 2011. [Online]. Available: https://files.eric.ed.gov/fulltext/EJ1118871.pdf [Accessed June 22, 2018].

[16] B. Robin, "The educational uses of digital storytelling," in Proceedings of Society for Information Technology \& Teacher Education International Conference, C. Crawford, R. Carlsen, K. McFerrin, J. Price, R. Weber \& D. Willis (Eds.), Chesapeake, VA: Association for the Advancement of Computing in Education (AACE), pp. 709-716, 2006.

[17] A. Paivio, Imagery and Verbal Processes. London, NY: Psychology Press, 2013.

[18] M. Thonghatta, "Effects of using Storybird to enhance creative English writing ability of Mathayomsuksa III students. In Proceedings of ISER 42nd International Conference, Tokyo, Japan, pp. 41-44, 2016.

[19] W. T. Chuang, et al. "Enhancing reading comprehension and writing skills among Taiwanese young EFL learners using digital storytelling technique," Indonesia: Asia-Pacific Society for Computers in Education. 2013. 
[20] J. A. Wertz, "Bitstrips and Storybird: Writing development in a blended literacy camp," Voices from the Middle, vol. 21, pp. 24-32, 2014.

[21] Zakaria et al., "Students' experience of using Storybird in writing ESL narrative text," Creative Education. 07. 2107-2120. https://doi.org/10.4236/ce.2016.715210.

[22] H. Seifeddin, et al. "A program based on English digital stories to develop the writing performance and reflective thinking of preparatory school pupils," Faculty of Education Magazine, vol. 8, no. 2, 2015.

[23] Yamaç, and M. Ulusoy, "The effect of digital storytelling in improving the third graders' writing skills," International Electronic Journal of Elementary Education. vol. 9. pp. 5986, 2016.

[24] A. P. Gilakjani, "Factors contributing to teachers' use of computer technology in the classroom," Universal Journal of Educational Research, vol. 1, no. 3, pp. 262-267, 2013.

\section{Authors}

Lim Pei Rong is a teacher at SMK Jalan Mengkibol, Kluang, Johor.

Norah Md Noor is a senior lecturer at School of Education, Faculty of Social Sciences and Humanities, Universiti Teknologi Malaysia. (norah@utm.my)

Article submitted 2019-05-04. Resubmitted 2019-06-04. Final acceptance 2019-06-10. Final version published as submitted by the authors 